\title{
Emergency Cesarean delivery for umbilical cord prolapse: the head-down, knee-chest prone position for spinal anesthesia
}

\author{
[Accouchement par césarienne d'urgence en raison d'un prolapsus du cordon \\ ombilical: la position de procubitus genu-pectoral, tête en bas, pour réaliser une \\ rachianesthésie] \\ Yehuda Ginosar MBBS, ${ }^{*}$ Carolyn Weiniger MBChв, ${ }^{*}$ Uriel Elchalal MD, $†$ Elyad Davidson MD*
}

\begin{abstract}
Objective: Umbilical cord prolapse in a parturient is an emergency, where the need for immediate fetal delivery may conflict with maternal anesthetic risk factors. We describe the anesthetic management of a parturient who was rushed to the operating room, in the knee-chest prone position, because of cord prolapse with variable decelerations of fetal heart rate.
\end{abstract}

Clinical features: A 28-yr-old multiparous patient presented at 37 weeks gestation. Her co-morbidities included morbid obesity and asthma. She had a Mallampati class IV airway. She required emergency Cesarean delivery, in view of umbilical cord prolapse, with evidence of fetal compromise. In light of the airway concerns, the urgency to proceed with delivery, and the presence of a palpable umbilical cord pulse in this position, we performed a spinal anesthetic in the knee-chest prone position, and immediately thereafter turned the patient supine, with lateral uterine displacement. Fetal heart rate was monitored throughout the procedure. The spinal anesthetic required less than five minutes to perform, from the time of skin preparation, until readiness for surgery. The subsequent surgical and anesthetic course was unremarkable.

Conclusions: Performing spinal anesthesia in the knee-chest prone position served as an innovative solution for emergency Cesarean delivery in this case. Both the head-down lateral, and the head-down knee-chest prone positions, are compatible with spinal anesthesia, and the maternal position that achieves relief of cord compression, determined by the presence of a palpable umbilical cord pulse, may be the most important factor to determine the optimal approach to spinal anesthesia.
CAN J ANESTH 2008/55: 9/pp 612-615

Objectif : Le prolapsus du cordon ombilical chez la parturiente est une situation d'urgence dans laquelle la nécessité d'un accouchement immédiat du fœtus peut entrer en conflit avec les facteurs de risques anesthésiques pour la mère. Nous décrivons la prise en charge anesthésique d'une parturiente qu'on a amené rapidement en salle d'opération, en position de procubitus genu-pectoral, en raison du prolapsus du cordon accompagné de décélérations variables de la fréquence cardiaque fœtale.

Éléments cliniques : Une multipare de 28 ans a été admise à 37 semaines de grossesse. Elle présentait des comorbidités d'obésité morbide et d'asthme. Elle avait des voies aériennes de classe IV selon le score de Mallampati. Elle a nécessité un accouchement urgent par césarienne, étant donné le prolapsus du cordon ombilical et la présence de signes de difficultés fotales. Étant donné les inquiétudes quant à la prise en charge des voies aériennes, l'urgence de provoquer l'accouchement et la présence d'un pouls palpable du cordon ombilical dans cette position, nous avons réalisé une rachianesthésie en position de procubitus genu-pectoral, puis avons immédiatement placé la patiente en décubitus dorsal, avec un déplacement utérin latéral gauche. La fréquence cardiaque fotale a été surveillée tout au long de l'intervention. La rachianesthésie a nécessité moins de cinq minutes avant d'être complète, du moment de la préparation de la peau au moment où tout était prêt pour la chirurgie. Il n'y a pas eu d'événements remarquables ni dans la suite de la chirurgie, ni du point de vue anesthésique.

From the Department of Anesthesiology and Critical Care Medicine, ${ }^{*}$ and the Department of Obstetrics and Gynecology, $†$ Hadassah Hebrew University Medical Center, Jerusalem, Israel.

Address correspondence to: Dr. Yehuda Ginosar, Director, Mother and Child Anesthesia Center, Department of Anesthesiology and Critical Care Medicine, Hadassah Hebrew University Medical Center, POB 12000, Jerusalem, Israel 91120. Phone: 972-2-6777111; Fax: 972-2-6434434; E-mail: yginosar@netvision.net.il

Competing interests: None declared.

Accepted for publication May 2, 2008.

Revision accepted May 26, 2008. 
Conclusion : Dans ce cas, le fait de réaliser une rachianesthésie en position de procubitus genu-pectoral a constitué une solution innovatrice pour rendre possible un accouchement par césarienne d'urgence. Les positions de procubitus latéral avec tête en bas et de procubitus genu-pectoral avec tête en bas sont toutes deux compatibles avec la rachianesthésie La position maternelle qui permet un soulagement de la compression exercée sur le cordon, identifié par la présence d'un pouls palpable du cordon ombilical, pourrait constituer le facteur prépondérant pour déterminer l'approche optimale pour la rachianesthésie.

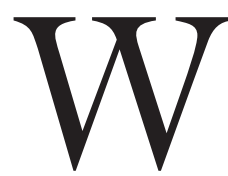

E report a case of umbilical cord prolapse requiring immediate Cesarean delivery in a parturient without an epidural catheter, where maternal medical risk factors and an anticipated difficult intubation strongly discouraged rapid sequence induction of general anesthesia. This case was managed by performing spinal anesthesia in the head-down, knee-chest prone position, while monitoring fetal heart rate. The patient gave consent for publication of this report.

\section{Case description}

A 28 yr-old woman with morbid obesity $(160 \mathrm{~cm}, 110$ $\mathrm{kg}$, body mass index $43 \mathrm{~kg} \cdot \mathrm{m}^{-2}$ ) was admitted in active labour at 37 weeks gestation, in her third pregnancy. Vaginal examination revealed a vertex presentation, with the fetal head positioned $2 \mathrm{~cm}$ above the ischial spines, and cervical dilatation at $4 \mathrm{~cm}$. The patient was not fasting. She had mild asthma, not treated by routine medications, with no history of recent exacerbations. She had no other active medical problems, and her current pregnancy had been normal. In the labour room, she received $500 \mathrm{~mL}$ Ringers' lactate $i v$, but she was not seen by an anesthesiologist at this stage.

One hour following admission, she had spontaneous rupture of membranes, followed by prolonged, variable fetal heart rate decelerations, to a nadir of 60 beats. $\mathrm{min}^{-1}$. Vaginal examination at this time revealed overt prolapse of the umbilical cord. She received oxygen by face-mask, additional intravenous fluid loading, and sodium citrate $30 \mathrm{~mL}$ per os. The operating room (OR) team was immediately called. The patient was placed on a trolley in the head-down, knee-chest prone position, and the midwife exerted continuous upward pressure on the fetal head from the vaginal approach, in accordance with local protocol. In this position, the patient was rapidly transferred to the OR, located within the labour ward.

On arrival in the OR, the cord was pulsating, and fetal heart rate had normalized to a rate of approximately $140 \mathrm{~min}^{-1}$ although with reduced beat-to beat variability. During the expedited anesthetic assessment, the patient was asked to raise her head for airway evaluation, while remaining in the knee-chest prone position. Two specific factors predicting likely difficult intubation were identified; she had Mallampati class IV airway, and morbid obesity.

In view of the identified risk factors for general anesthesia (predicted difficult tracheal intubation, emergency surgery, morbid obesity, advanced pregnancy, recent meal, bronchial asthma) and in view of the reassuring presence of a normal fetal heart rate in the head-down, knee-chest prone position, a decision was made to perform a spinal anesthetic in this position. It was our view that rapid sequence induction was contraindicated, that awake fibreoptic intubation would likely have taken longer to perform (including the time which would have been required to prepare the airway), and that changing the patient position to facilitate a regional block might jeopardize umbilical cord blood flow.

The patient was co-operative and, after a brief explanation, consented to regional anesthesia. The patient was given oxygen via face-mask, and standard monitors were applied. Electronic fetal heart rate monitoring was maintained throughout. With the anesthesiologist standing on footstools, the patient's back was rapidly prepped for spinal anesthesia. The midline and spinal interspaces were easily identified. A $22-27 \mathrm{G}$ spinal needle $(22 \mathrm{G}$ shaft, $27 \mathrm{G}$ pencil point tip; Polymedic, Temena International, Carriere-surSeine, France) was inserted easily into the subarachnoid space at the L3/4 interspace, using a midline approach. In anticipation of the possible reduction in cerebrospinal fluid flow in this position, a syringe was attached to the spinal needle after the needle tip was felt to have passed the dura, and cerebrospinal fluid was aspirated. Hyperbaric bupivacaine $11 \mathrm{mg}$ (with $100 \mathrm{mg}$ dextrose), fentanyl $20 \mu \mathrm{g}$, and preservativefree morphine $150 \mu \mathrm{g}$ were administered via the spinal needle, as a single shot technique; these are routine doses of spinal anesthetic drugs in our institution for emergency spinal anesthesia.

Immediately following intrathecal drug administration, the patient was turned to the supine position with a wedge placed under her right hip. The bed was initially placed in a slightly head down position, to encourage cephalad progression of the block, but this was discontinued after two to three minutes, as the block height progressed. The patient had a block level of T10 at first examination, one to two minutes after assuming the supine position. The spinal anes- 
thetic took less than five minutes from the initiation of skin preparation until readiness for surgery (sensory level T6). The fetus was delivered with Apgar scores of 9 and 10, at one and five minutes, respectively. At no point during surgery did the patient experience any pain, or express the need for additional anesthetic. Maternal blood pressure was relatively stable, with a peak blood pressure of $135 / 70 \mathrm{mmHg}$ on admission to the OR, and a nadir of $95 / 60 \mathrm{mmHg}$ five minutes after spinal drug administration; a $100 \mu \mathrm{g}$ bolus of phenylephrine was administered twice to maintain maternal blood pressure. The maximum sensory level was $\mathrm{T} 4$, and the subsequent surgical and anesthetic course was unremarkable.

Although the anesthesia plan was successful, we had prepared contingency plans. During block placement, an anesthesia assistant readied the difficult intubation kit and a fibreoptic bronchoscope. After block placement, several rolled towels were placed under the patient's shoulders, in case of unanticipated need for urgent tracheal intubation during surgery.

\section{Discussion}

Umbilical cord prolapse is almost always a category 1 indication for urgent Cesarean delivery. ${ }^{1}$ In our practice, women with cord prolapse, without an epidural catheter in situ, usually receive general anesthesia for emergency Cesarean delivery, although $77.6 \%$ of obstetric anesthesiologists of the Obstetric Anaesthetists' Association disagreed that cord prolapse mandates general anesthesia. ${ }^{2,3}$ The choice of general anesthesia for category 1 emergency Cesarean delivery is based upon the assumption that the time between the start of anesthesia care, and patient readiness for surgery, is shorter with general anesthesia compared to regional anesthesia, and that this time difference may influence fetal outcome.

In the Confidential Enquiry into Stillbirths and Deaths in Infancy in the United Kingdom (1994-5), anesthesia was identified as either the direct, or the contributory cause of death of 25 neonates. In ten of these cases, the technical difficulty in finding the epidural or intrathecal space led to a delay that was judged to have been a factor contributing to neonatal death. ${ }^{4}$ In a prospective study of emergency Cesarean deliveries $^{5}$, general anesthesia was associated with a much shorter decision-to-delivery interval (DDI) than spinal or epidural anesthesia $(23 \mathrm{~min}, 60 \mathrm{~min}$ and 45 min respectively). However, DDI is dependent upon multiple "obstetric time" factors. For increasingly urgent obstetric conditions, the "obstetric time" shortens, and the incidence of general anesthesia rises. ${ }^{6}$ Decision-to-delivery interval in non-random- ized studies is highly susceptible to self-selection bias, a supposition supported by the fact that fetal acidemia worsens as the DDI shortens. ${ }^{1,5}$ Dyer et al. ${ }^{7}$ measured the anesthesia induction-to-surgical incision interval (AISII) in a prospective, randomized controlled trial of spinal and general anesthesia for emergency Cesarean delivery for pre-eclampsia with fetal distress. There was only a modest difference in the AISII for general (four minutes) and spinal (six minutes) anesthesia. Furthermore, the short AISII for general anesthesia is only relevant for rapid sequence induction. In the case presented, with signs of anticipated difficult intubation, an awake fibreoptic intubation may have been appropriate with a general anesthetic technique, but would likely have taken several minutes longer than the time needed for regional anesthesia.

Standard management for intra-uterine resuscitation in the event of umbilical cord prolapse includes direct manual pressure to raise the fetal head via the vaginal approach, and placing the patient in either the headdown lateral, or head-down knee-chest position. ${ }^{8}$

Inducing spinal anesthesia in the sitting position requires spending valuable time repositioning the patient, and may further exacerbate fetal compromise by increasing fetal head pressure on the loop of prolapsed umbilical cord. Inducing spinal anesthesia in the lateral position may be complicated by the reduced ability to identify the midline and the spinal interspaces, ${ }^{9}$ but may be the best option for regional block in centres where the policy is to transport women with cord prolapse to the OR in the head-down lateral position. In many institutions including our own, women are transported in the head-down, knee-chest prone position. This is not dissimilar to the jackknife position used for the spinal administration of hypobaric local anaesthetics for peri-anal surgery. ${ }^{10-12}$ This position provides a demarcation of the midline, as clear as that seen in the sitting position. Performing spinal anesthesia in both the lateral and the knee-chest positions avoids the need to reposition the woman twice, prior to, and following anesthesia, and allows both continued manual pressure on the fetal head via the vaginal route and continued fetal heart rate monitoring.

Several studies have compared the administration of spinal anesthesia for Cesarean delivery in the sitting, right lateral, left lateral and Oxford positions, ${ }^{13-16}$ but the experience of administering spinal anesthesia in the prone position has not been reported previously. We were concerned that the spread of hypobaric local anesthetic in the prone position might be unpredictable, and that hyperbaric bupivacaine would allow block level to be controlled by the manipulation of the angle of the operating table. The interaction 
of baricity and posture on the spread of spinal local anesthetics has been studied; while there were minimal differences between anesthetics of different baricity in the lateral position, the height of the sensory level, the incidence of cervical block, and the degree of hypotension all increased with decreasing baricity in the sitting position. ${ }^{17}$ The importance of hemodynamic stability in this patient was compounded by the pre-existing compromised umbilical cord blood flow, and by the need to avoid compromising the maternal airway. The knee-chest prone position has been associated with a modest increase in hemodynamic lability following spinal anesthesia. ${ }^{17}$ When compared to the spinal administration of $15 \mathrm{mg}$ plain spinal bupivacaine in the lateral position, spinal anesthesia in the knee-chest position was associated with a greater change in mean arterial pressure $(-30 v s-13 \mathrm{mmHg})$, increased ephedrine utilization $(6 / 20 v s 3 / 20$ patients), and increased bradycardia (4/20 vs $2 / 20$ patients). ${ }^{12}$ Accordingly, the choice of hyperbaric bupivacaine in this patient, and in this position, seems to have been appropriate.

In summary, umbilical cord prolapse is an emergency situation where the need for immediate fetal delivery may conflict with maternal anesthetic risk factors. We present a parturient who was rushed to the OR in the knee-chest prone position, because of cord prolapse, with variable decelerations of fetal heart rate. In view of her morbid obesity, asthma, and a Mallampati class IV airway, performing spinal anesthesia in the knee-chest prone position served as an innovative solution for emergency Cesarean delivery in this case. Both the head-down lateral position, and the headdown knee-chest prone position, are compatible with spinal anesthesia. The maternal position that achieves relief of cord compression, determined by the presence of a palpable umbilical cord pulse, may be the most important factor to determine the optimal approach to spinal anesthesia.

\section{References}

1 Bloom SL, Leveno KJ, Spong CY, et al. Decision-to-incision times and maternal and infant outcomes. Obstet Gynecol 2006; 108: 6-11.

2 Bythell $V$. Cord prolapse demands general anaesthesia. Int J Obstet Anesth 2003; 12: 287-9.

3 Scrutton $M$. Cord prolapse demands general anaesthesia. Int J Obstet Anesth 2003; 12: 290-2.

4 CESDI. Obstetric Anesthesia Delays and Complications. Confidential Enquiry into Stillbirths and Deaths in Infancy 2000 (7th annual report). London: Maternal and Child Health Research Consortium. 2000: 41-52.
5 MacKenzie IZ, Cooke I. What is a reasonable time from decision-to-delivery by caesarean section? Evidence from 415 deliveries. BJOG 2002; 109: 498-504.

6 McCahon $R A$, Catling $S$. Time required for surgical readiness in emergency caesarean section: spinal compared with general anaesthesia. Int J Obstet Anesth 2003; 12: 178-82.

7 Dyer RA, Els I, Farbas J, Torr GJ, Schoeman LK, James $M F$. Prospective, randomized trial comparing general with spinal anesthesia for cesarean delivery in preeclamptic patients with a nonreassuring fetal heart trace. Anesthesiology 2003; 99: 561-9.

8 Boyle JJ, Katz VL. Umbilical cord prolapse in current obstetric practice. J Reprod Med 2005; 50: 303-6.

9 Felsby S, Juelsgaard P. Combined spinal and epidural anesthesia. Anesth Analg 1995; 80: 821-6.

10 Wolff $R C, U p p C W$. The prone jackknife position for the administration of spinal anesthesia: a two-year study. Anesth Analg 1963; 42: 375-8.

11 Maroof $M$, Khan RM, Siddique M, Tariq $M$. Hypobaric spinal anaesthesia with bupivacaine $(0.1 \%)$ gives selective sensory block for ano-rectal surgery. Can J Anaesth 1995; 42: 691-4.

12 Laasko E, Pitkanen M, Kytta J, Rosenberg PH. Kneechest vs horizontal side position during induction of spinal anaesthesia in patients undergoing lumbar disc surgery. Br J Anaesth 1997; 79: 609-11.

13 Inglis $A$, Daniel $M$, McGrady E. Maternal position during induction of spinal anaesthesia for caesarean section. A comparison of right lateral and sitting positions. Anaesthesia 1995; 50: 363-5.

14 Russell R, Popat M, Richards E, Burry J. Combined spinal epidural anaesthesia for caesarean section: a randomised comparison of Oxford, lateral and sitting positions. Int J Obstet Anesth 2002; 11: 190-5.

15 Rucklidge $M W$, Paech MJ, Yentis SM. A comparison of the lateral, Oxford and sitting positions for performing combined spinal-epidural anaesthesia for elective caesarean section. Anaesthesia 2005; 60: 535-40.

16 Coppejans HC, Hendrickx E, Goossens J, Vercauteren $M P$. The sitting versus right lateral position during combined spinal-epidural anesthesia for cesarean delivery: block characteristics and severity of hypotension. Anesth Analg 2006; 102: 243-7.

17 Hallworth SP, Fernando R, Columb MO, Stocks GM. The effect of posture and baricity on the spread of intrathecal bupivacaine for elective cesarean delivery. Anesth Analg 2005; 100: 1159-65.

18 Richardson MG, Collins HV, Wissler RN. Intrathecal hypobaric versus hyperbaric bupivacaine with morphine for cesarean section. Anesth Analg 1998; 87: 336-40. 